\title{
Disrupting Medical Education
}

\author{
Fauzia Nausheen* \\ Department of Medical Education, California University of Science and Medicine, USA
}

*Corresponding author: Fauzia Nausheen, Department of Medical Education, California University of Science and Medicine, 217 E, Club Center Drive, Suite A, San Bernardino, CA 92408, USA.

To Cite This Article: Fauzia Nausheen, Disrupting Medical Education. 2020 - 7(6). AJBSR.MS.ID.001216. DOI: 10.34297/AJBSR.2020.07.001216.

Received: 此 February 29, 2020; Published: March 06, 2020

\section{Introduction}

In order to develop interest of medical students of new age in medical education, the institutions incorporate recent advanced technology by creating innovative curriculum. These institutions strive to develop in class teaching methodologies for student's attendance and engagement in spite of the media availability of connective knowledge through Massive Online Courses (MOOCs) $[1,2]$. The teaching is trending towards non-traditional, mobilebased, social media influenced curricula and schools are trying their best to get effective outcomes out of these non-traditional curricula. Also, there is an effort put in by the medical education to develop an empathy in future doctors trained by simulations, robots and augmented reality.

Some of the examples of medical disruption are using advanced technology for student engagement, adaptive quizzing, collaborative learning and better training. For instance, we implemented view board display content sharing and interactive touch to boost virtual histology learning. Some health care institutions use augmented reality, virtual anatomy and ultrasonographic living anatomy to learn the 3D concepts. Several advanced clinical curricula use robotic and artificial intelligence to augment the diagnostic ability of physicians. Health care institutions struggle to teach the ethics, values and community centered services by opportunity of direct contact with underserved community by innovative programs like neighborhood care, home care and health screening. The most part of this preventive care education of patients is delivered by using skype calling, videos recordings, and use of telehealth to stay in contact with communities. In order to cultivate the sense of responsibility, ownership of choices and decision and value consciousness, the curricula are designed with embedded simulated sessions, high tech hands-on workshops and role-playing. Another important arm of curriculum is to create the skills of lifelong learning among future physicians, vision to recognize the current and future challenges of health care and find innovative solutions that they can learn and practice through the simulated environment created by role playing.

\section{Intended Outcome}

One of the screening method for admission can use the NEO personality scale [3] for selecting medical students who should be able to cope with stress of medical schools, able to enjoy innovative trends in medical education but keeping the values and mindset of an empathetic physician. The emphasis should be on communication and hands-on skills than knowledge only. Medical school and health care institutions should create among their future physicians: team spirit, adaptability and a patience to accept people with their shortcomings. The emphasis should also be on developing the skills to serve as leaders that can take the responsibility and make conscientious decisions. It is important for future physicians to have an understating of the challenges in provision of health care to undeserved communities by implementing the high-tech digital medicine. The future doctors and other health care professional of new age should develop the mindset of learning as part of life- long process and always remembering the goal of serving the patients [4].

\section{References}

1. Molly Cooke, David M Irby, Bridget C O’Brien (2010) Educating Physicians: A Call for Reform of Medical School and Residency. J Chiropr Educ 25(2): 193-195.

2. Neil M, Hull A, Young J, Stoller J (2013) Just Imagine: New Paradigms for Medical Education. Academic Medicine 88(10): 1418-1423.

3. Revised NEO Personality Inventory.

4. Yeoh K G (2019) The future of medical education. Singapore Med J 60(1): 3-8. 